\title{
An Analysis of the Precautionary Principles and Its Adaptation in International, Regional and National Laws
}

\author{
Mark Akunna Eze ${ }^{1}$, Ifeanyi Samson Eze ${ }^{2}$ \\ ${ }^{1}$ Department of Mass Communication, School of Communication Arts, Institute of Management and Technology (IMT), Enugu, Nigeria \\ ${ }^{2}$ Department of Pure and Industrial Chemistry, Faculty of Physical Sciences, University of Nigeria, Nsukka, Nigeria
}

Email address:

m.eze.co.ng@gmail.com (M. A. Eze)

\section{To cite this article:}

Mark Akunna Eze, Ifeanyi Samson Eze. An Analysis of the Precautionary Principles and Its Adaptation in International, Regional and National Laws. International Journal of Energy and Environmental Science. Vol. 4, No. 3, 2019, pp. 47-51. doi: 10.11648/j.ijees.20190403.12

Received: May 16, 2019; Accepted: June 20, 2019; Published: August 6, 2019

\begin{abstract}
There is risk in every human activity. Statistics indicate that these risks are earth bound. Arguments as to whether policies meant to check and control these risks based on scientific evidence or on mere suspicion of risks have formed the subject of debate in many international conferences. Some persons agree that decisions to protect/prevent risk must be based on clear evidence of risk, others believe that mere suspicion with or without any clear evidence of risk is enough to warrant such policies. Risk is measured not only by positive knowledge of quantifiable but also by the degree of uncertainty or lack of knowledge about a possible hazard... On the continuum, between, a merely speculative risk and a conclusively demonstrated one lies a vast stretch of undemonstrated, un-quantified but scientifically plausible risk. Within that zone, the risk of harm is real so long as safety is unproven. It is this broad spectrum of potential risk, beyond that which is clearly identifiable and preventable that the precautionary principles, the roots of which lie in the environmental movements of the 1970s, seek to mitigate. This work set out to examine the precautionary principle as an environmental policy, its origin, meaning, importance and adaptation in international, regional, and domestic Laws. This study applied desk approach in generating data for the study. The result indicates that though the principle has become an established principle of environmental law particularly at international level, it is yet to be legitimately invoked and applied by most national laws.
\end{abstract}

Keywords: Precautionary, Principles, Adaptation and Laws

\section{Introduction}

According Mark Stallworthy, "the management of risk is ultimately a political question, and the levels of propriety and acceptability are dependent upon the availability/quality of technical scientific assessment. The further from certainty we are, the more politically problematic the decision. What is known as the precautionary principle is increasingly the subject of broad, formulaic, declarations by international bodies." [1] Risk is measured not only by positive knowledge of quantifiable but also by the degree of uncertainty or lack of knowledge about a possible hazard... [2] On the continuum, between, a merely speculative risk and a conclusively demonstrated one lies a vast stretch of undemonstrated, un-quantified but scientifically plausible risk. Within that zone, the risk of harm is real so long as safety is unproven. [3] It is this broad spectrum of potential risk, beyond that which is clearly identifiable and preventable that the precautionary principles, the roots of which lie in the environmental movements of the 1970s, seek to mitigate.

This work sets out to critically examine the precautionary principle as an environmental policy, its origin, meaning, importance and adaptation in international, regional, and domestic Laws.

\section{Meaning of Precautionary Principle}

It is a principle which warrants the taking of regulatory action to protect health and environment in the absence of conclusive evidence of harm. [4] Precautionary action refers to restrictions adopted where, for instance, the majority of the scientific community considers a particular product safe for consumption, but a minority opinion argues that there are risks in case of prolonged exposure. It refers to action undertaken against activities identified as potentially dangerous on the basis of a preliminary risk assessment, while awaiting the 
result of a more thorough, fully quantified" risk assessment. [5] Fundamental to this principle is the idea that precaution shall be taking with respect to the protection of the environment or human health even if there is no clear evidence of harm or risk of harm from an activity or substance. [6] The aim of the policy is to encourage policy makers to avoid such activities that are capable of putting the society as a whole or a segment of it-at risk from the unexpected side effect of a certain type of policy. [7] Therefore, at the core of the early conceptions was the belief that regulatory agencies and government should move to minimize environmental risks by anticipating possible danger and if possible prevent it. [8]

\section{Origin of the Principle}

The history of precautionary principle dates back to the early days of civilization, because the oral tradition of many indigenous peoples had the concept of precautionary principle embedded in them. [9] The development of the precautionary principle is rooted in the following maxim; (1) it is better to err on the side of caution, even where there is no evidence of harm; and (2) it is better to be safe than sorry. [10] What is today known as precautionary principle can be traced to the German concept of Vosorgeprinzip which means that in cases where serious harm is threatened, positive action to protect the environment should not be delayed until irrefutable scientific proof of harm is available. [11] Inspired by its use in Swedish and German Environmental Law and Policy, the precautionary principle was first employed internationally in the North Sea Conference in 1984 and later affirmed by EC governments in the 1990 Bergen Ministerial Declaration on Sustainable Development. [12] Based on this, a text proposed by the European Union secured global endorsement in the 1992 Rio Declaration on Environment and Development. Principle 15 of the Declaration says.

In order to protect the environment, the precautionary approach shall be widely applied by states according to their capabilities. Where there are threats of serious or irreversible damage, lack of full scientific certainty shall not be used as a reason for postponing cost-effective measures to prevent environmental degradation.

\section{Critical Examination of the Principle and Its Relevance as Environmental Policy}

Precautionary principle encourages humanity to be proactive rather than reactive and reminds men of the old saying that prevention is better that cure. According to Patricia Birnie et al, the approach is innovative in that it changes the role of scientific data. It requires that once environmental damage is threatened, action should be taken to control possible environmental interference even though there may still be scientific uncertainty as to the effects of the activities. This according to the authors does not mean that science ceases to be relevant in judging the existence of risk, or that states are required to act on the basis of mere hypothesis or purely theoretical assessment of risk. In Landelijke Vereniging tot Behoud Van de Wadden Zee's case the European Court of Justice described the principle as "one of the foundations of high level of protection pursued by the community policy". [13] Indeed, the implications of precautionary principle are significant: as a statement of policy, it calls for changes in the way decisions about the environment are made, and for new forms of interactions among scientists, legislators and members of the public. [14] In the 2000 Communication, the EU described the principle as a "central plank" of community policy, a sentiment that was echoed by the Court of First Instance in Alpharma Inc. V. Council. [15] The idea is to ensure that environmental protection is achieved without having to wait until the cause and the effect of their adverse environmental impact is established. So, precautionary principle is intended to prevent the use of scientific uncertainty as an excuse to justify inaction in the face of potential threats to the environment. [16] This principle appreciates that no matter the level of sophistication in respect of science and technology, there are certain risk that may not yield to any explanation. Therefore, as long as there is suspicion of such risk caution must be taken. The argument that one has done it once and succeeded cannot hold because the next step may be dangerous. According to Nassim et al, "certain class of risk will remain inherently unknown. Some classes of complex systems, controlled experiments cannot evaluate all possible systemic consequences under real word conditions". [7]

The principle is comprised of three negatives: no scientific uncertainty does not mean that no measure should be taken; it set fort no positive obligation; it simply reminds legislators that they cannot wait for proof of a cause-effect linkage between a given substance, process or activity and environmental harm before acting to reduce or eliminate the risk of this harm. [17]

However, the principle has incited an astonishing amount of interest, attention, and controversy. Not everyone is swayed by the alleged importance of the principle. In 2003 publication, Noelle Eckley and Henrik Selin described the precautionary principle as "all talk and little action". [18] Also, in Pfitzer's case, the European Court put it that a preventive measure cannot properly be based on a purely hypothetical approach to risk, founded on mere conjecture which has not been scientifically verified. [19] To others, decision making on the basis of the principle is a political one deriving from the nature of the principle as a principle which is distinct from rules. [20]

\section{Adaptation of the Principle in International, Regional, and National Laws}

\subsection{International Law}

At the international level, the principle was first recognized in the World Charter for nature, adapted by the 
UN General Assembly in 1982. [21] The principle was implemented in an international treaty as early as the 1987 Montreal Protocol. The most often cited version of the principle appears in the 1992 Rio Declaration on Environment and Development as Principle 15. [14] According to the Principle 15 of the Rio Declaration;

In order to protect the environment, the precautionary approaches shall be widely used by states according to their capabilities. Where there are threats of serious and irreversible damage, lack of full scientific certainty shall not be used as reason for postponing cost-effective measures to prevent environmental degradation. [22]

The Rio Declaration contains three attributes: [1] a potential future harm - in this case, "serious and irreversible damage"; [2] an implicit or explicit requirement for a real basis for concern - "threat" not speculation; and [3] action to prevent harm before scientific certainty has been achieved. [23]

It is important to note that, the principle began in the form of policy statements and finally in the operational provisions of international conventions and in a number of international environmental protection regimes. For instance, the 1985 Ozone Convention and its 1987 Montreal Protocol are perhaps the examples of the application of the principle in the form found in Principle 15 of the Rio Declaration because they required action on the part of states before the casual link between Ozone depletion and CFCs had been conclusively demonstrated.

Since 1990, the principle has equally found its way in a growing number of international treaties which includes; UN Framework Convention on Climate Change, 1992; [24] Convention on Biological Diversity, 1992 in its preamble noted ...where there is significant reduction or loss of biological diversity, lack of full scientific certainty should not be used as a reason for postponing measures to avoid or minimize such a threat; The Maastricht Treaty of European Union, 1992; Cartagena Protocol on Bio-Safety, 2000 and Stockholm Convention on Persistent Organic Pollutants (POP), 2001. [25] The approach was also adopted in relation to the reduction of radioactive and other hazardous substances under the 1992 OSPAR convention. [26]

However, it is important to note that similar to sustainable development, precautionary principle has found a limited number of case laws to support it. In New Zealand v. France, Judge Weeramantry was of the opinion that notwithstanding the increased support gained by principle as part of the international law on environment, it should be used only where there was insufficient material before the court to justify the action, even if this meant acting ahead of 'full scientific evidence. [27] Also in the New Zealand v. Japan, Judge Laing rejected the notion that precautionary principle was a customary international law. He was of the view that adopting an approach, rather than a principle, was more flexible and highlighted the problems of making 'premature pronouncements about desirable normative structures' in cases of risk and scientific uncertainty. [28]

\subsection{Regional Laws}

At the regional level, the EU for example, has adopted laws, treaties, and conventions which have precautionary principle as its cardinal objective. It was elevated to a legally binding principle of European environmental law through its incorporation in Article 130r (now 174) of E. C. Treaty in 1992. The Maastricht revisions to the treaty formalized its position by introducing the requirement that, in addition to the principles of prevention and rectifying damage at source, "the" principle should underpin all European environmental regulation. [2]

In 2000, the European Commission issued a communication on the principle in which it adopted a procedure for the application of this concept thus;

Union policy on the environment shall aim at a high level of protection taking into account the diversity of situations in the various regions of the Union. It shall be based on the precautionary principle and on the principles that preventive action should be taken, that environmental damages should as a priority be rectified at source and that the polluter should pay. [29]

The adoption of Commission's Communication on this principle has influenced much of EU policy on environment. As at 2006, the principle has been integrated into EU laws e.g. general product safety, the use of additives for animal nutrition, the incineration of waste and regulation of genetically modified organisms. A good example is Directive 90/219/EEC and 90/220/EEC (repealed by Directive 2001/18/EC) which were negotiated against the background of a clear European shift towards a more precautionary approach to environmental regulation. [2]

In Africa for instance, member nations are faced with the new policy challenges arising from the pressure to apply the precautionary principles in decision making. Cameroon, Egypt, Uganda, and Zambia-made explicit reference to the precautionary principle with respect to Biosafty regulations. [30] This resulted from the growing international debate on safety of Genetically Modified Products (GMP) of modern biotechnology and the adoption of the Cartagena Protocol on Biosafety. However, there is doubt with respect to the extent to which the principle has translated into specific policies in these African countries. It is even more disturbing considering the growing famine and food insecurity in Africa. The question is whether, countries in Africa can implement this policy under this condition.

\subsection{National Laws}

At the domestic level, the policy is found in the laws of Australia, France, Germany, India etc. In India for instance, they see precautionary principle as part of the customary international laws (and hence part of the domestic laws). In fact, the Indian Court has applied the reversal of burden of proof and demanded that proponents of the activity must demonstrate that the activity is environmentally benign. [31] In Calcutta Tanneries Case, the Indian Supreme Court while applying the principle ordered the polluting Tanneries 
operating in the city of Calcutta to relocate themselves from their present location and shift to the new leather complex set up by the West Bengal Government. [32] In Badkhal \& Surajkund Lakes Case, the court noted that the principle made it mandatory for government to prevent and attack the causes of environmental degradation. [33]

In United Kingdom for instance, the first detailed references to the Precautionary Principle can be seen in the government White Paper, in 1990 known as the 'This Common Inheritance'. This was considered a weak form of Precautionary Principle since action will be taken where there is 'significant risk' even in cases of scientific uncertainty if the 'balance of costs and benefits' justified it. [28] Though this is considered a firm policy statement and a commitment to the idea of Precautionary Principle, it is yet to be incorporated into domestic legislation and thus there are no statutory obligations to achieve the PP. According to Jordan and O'Riordan, though the Principle is implicit in much UK legal language, in practice, it is still interpreted in favour of economic development rather than nature of conservation. [8]

In Nigeria for instance, there are a handful of legal framework that encourage responsible use of the environment. These include, Nigeria Communication Act, 2003, National Environmental Standard and Regulations Enforcement Agency (Establishment) Act, 2007 (NESREA ACT), Environmental Impact Assessment (EIA) Act, 1992, Harmful Waste (Special Criminal Provision) Act, Cap H, 1 LFN, 2004, Federal Environmental Agency Act, Cap F. 10 LFN, 2004 and Associated Gas Re-injection Act, Cap 20 LFN, 1990.

Note that while the Harmful Waste (Special Criminal Provision) Act, 2004 prohibits the carrying, dumping and deposition of harmful waste or any injurious, poisonous or toxic substances which is capable of subjecting anybody to risk of death on any land or territorial waters of Nigeria, the Environmental Impact Assessment Act No. 86 of 1992 is the direct response to the outcome of United Nations Conference on Environment and Development (UNCED) held in Rio de Janeiro in 1992. The Associated Gas Re-injection Act, Cap 20 LFN, 1990 prohibits gas flaring associated with oil and gas exploration and exploitation and the resultant atmospheric pollution particularly as it affects the depletion of the ozone layer.

A critical examination of these laws indicates that all of them gear towards the realization of the same objectives pursued by the precautionary principles, particularly the EIA Act. A close look at the EIA Act reveals the following objectives;

To establish the likely environmental impact of a proposed activity before a decision is taken to implement it.

To promote the implementation in all federal lands, state and local government areas of appropriate policies consistent with all laws and decision-making processes through which the above goals may be reached; and

To encourage the development of procedures of information exchange, notification and consultation between institutions and people when proposed activities are likely to have a significant effect on boundary or trans-state or on the environment bordering towns and villages.

The EIA Act has mandated an inquisition into any proposed project just like the precautionary principle. The difference if any is whether a proposed project under the EIA report without scientifically proven result as to the consequences of the project will be allowed to go on even when there is suspicion of adverse effect as against the precautionary principle which states that uncertainty should not be an excuse ones there is sign of danger with respect to a proposed project, that project should not be allowed to go on. However, at the root of both policies is the fact that it is better to be safe than to be sorry.

\section{Conclusion}

Notwithstanding the uncertainties in terms of application and its implication, the principle which forms part of environmental policy has become part of the international, regional and national laws and as such should be embraced by all. Philippe Sands et al notes that, in order to achieve sustainable development, policies must be based on precautionary principle. Environmental measures must anticipate, prevent and attack the cause of environmental degradation. [34]

Thus, in De Brett Investments Pty Ltd and Anor and Australian Fisheries Management Authority, [35] the Administrative Appeals Tribunal (AAT) stated that "the precautionary principle is still regarded as requiring that caution be exercised but only in situations in which it is established, on the balance of probabilities, that serious or irreversible environmental damage can reasonably be expected if a certain course of action is taken." The Tribunal further defined and interpreted the core elements of precaution such as 'threat' and 'full scientific certainty' for the purposes of applying precaution as follows:

Where there is a threat of serious or irreversible environmental damage, there is some aspect that gives an indication that there will be serious or irreversible damages if a certain course is followed. That aspect needs to be established on the balance of probabilities for, in the absence of any contrary indication in the Act, it is the civil standard of proof that is adopted. Just as the civil standard is not a fixed standard in all cases but adapts according to the seriousness of the issue under consideration in accordance with the principles in Briginshaw v. Briginshaw so too does the standard of proof where the precautionary principle is concerned. [36]

Though the principle has become an established principle of environmental law particularly at international level, it is yet to be legitimately invoked and applied by most national laws.

\section{References}

[1] S. Mark, "Genetically Modified food, Regulation and free Trade: A Saga for Our Times," (International Company and Commercial Law Review, 2003) p. 23-37. 
[2] S. Naomi, "A European Perspective on the Precautionary Principle, Food Safety and the Free Trade Imperative of the WTO," (European Law Review, 2002) p. 138-155.

[3] V. R. Walker, "Keeping the WTO from Becoming the World Trans Science Organisation: Scientific Uncertainty, Science policy and Fact Finding in the growth Hormones Dispute", 1998, (Cornell L. J., 1998) p. 305.

[4] H. Veerle, "Facing the Consequences of the Precautionary Principle in European Community Law," (European Law Review, 2006) p. 185-206.

[5] L. Maria, EU Environmental Law Challenges, Changes, and Decision-Making, (Oxford: Hart Publishing, 2002) p. 99-100.

[6] S. Bell and D. McGillivray, Environmental Law, (Oxford University Press, 2008), p. 63.

[7] Nassim Nicholas Taleb et al, "The Precautionary Principle with Application to the Genetic Modification of Organisms, New England Complex Systems Institute", Institute of Mathematics and Theoretical Physics, C. N. R. S, Paris, School of Philosophy, University of East Anglia, https://arxiv.org/pdf/1410.5787.pdf.

[8] Andrew Jordan \& Timothy O'Riordan, The Precautionary Principle in UK Environmental Law and Policy, https://link.springer.com/chapter/10.1007/978-1-349-24237-5 5. Assessed 13/04/18.

[9] P. H. Martin, "If You Don't Know How to Fix it Please Stop Breaking it; The precautionary Principle and Climate Change," (Foundation of Science, 1997) p. 263-292.

[10] H. Guldberg, "Challenging the Precautionary Principle: How has the Society come to be Governed by the Maxim "Better Safe than Sorry," available at http://salascove.com/dioxin2007/organisedparanoia.pdf assessed 13/10/15.

[11] S. O. Nliam, "International Oil and Gas Environmental Legal Framework and the Precautionary Principle: the Implication for Niger Delta", (African Journal of International and Comparative Law, 2014) p. 22-39.

[12] B. Patricia et al, International Law and the Environment, (Oxford University Press, 2009) p. 154.

[13] Landelijke Vereniging tot Behoud Van de Wadden Zee's case (2004) E. C. R, 1-7405.

[14] E. Jaye, "Overexploitation of a Valuable Resources; New Literature on the Precautionary Principle," (European Journal of International Law, 2006) p. 445-462.

[15] Alpharma Inc. V. Council (2002) 11 E. C. R 3305, para. 143.

[16] C. Ilona, "The Precautionary Principles in EC and WTO Law; Searching for a Common Understanding", (Environmental Law Review, 2006) p. 257-277.

[17] C. Stone, "Is there a Precautionary Principle?" (Environmental Law Reporter, 2001) p. 10790.
[18] E. Noelle, and S. Henrik, "All Talk, Little Action: Precautionary and the European Chemical Regulation," (Journal of European Public Policy, 2004) p. 78-105.

[19] Pfitzer Animal Health V. Council of the EU, (2002) 11 E. C. R 3305, para. 143.

[20] R. Dworkin, Taking Rights Seriously, (Harvard University Press, 1977) p. 24-26.

[21] L. M. Harewood, "The Importance of Precautionary Principle in International Environmental Law," (Coventry Law Journal, 2005) p. 1-5.

[22] Rio 7 UNEP Declaration on Environment and Development. Nairobi: United Nations Environment Programme, 1992. Available from: http://www.unep.org/Documents.Multilingual/Default.asp?doc umentid=78\&articleid=1163, Accessed April 13, 2018.

[23] Kenisha Garnett, \& David J. Parson, "Multi-Case Review of the Application of the Precautionary Principle in European Union Law and Case Law", available from https://onlinelibrary.wiley.com/doi/full/10.1111/risa.12633. Assessed 13/04/18.

[24] Art. 3 (3) of the 1992 Framework Convention on Climate Change.

[25] S. Manisha, "Be Legal, Be Intelligent; Precautionary Principle of Environmental Law," http://newindialaw.blogspot.co.uk/2013/05/precautionary-prin ciple-of. html. assessed 16/10/15.

[26] B. Start, \& M. Donald, Environmental Law, (Oxford University Press, 2006) p. 71.

[27] New Zealand v. France (1995) ICJ Rep 288.

[28] New Zealand v. Japan (2001), ILR 148.

[29] J. Morris, "Redefining the Precautionary Principle," in Morris, J., (ed) Rethinking Risk and the Precautionary Principle, (Butterworth Heinmann, 2000) p. 7.

[30] John Mugabe, "Precautionary Policies and Biotechnology in Africa", (Institute for Agriculture and Trade Policy, 2000), https://www.iatp.org/news/precautionary-policies-and-biotech nology-in-africa.

[31] A. K. Tiwari, Environmental Laws in Indian, 2006, (Deep and Deep Publications PVT Ltd, 2006) p. 216.

[32] Calcutta Tanneries Case (1997) 2 SCC 411.

[33] Badkhal \& Surajkund Lakes Case (1997) 3 SCC 715.

[34] S. Philippe et al, Principle of International Environmental Law, (Cambridge University Press, 2012) p. 219.

[35] Re De Brett Investments Pty Ltd and Anor and Australian Fisheries Management Authority (2004) 82 ALD 163 at 207.

[36] Briginshaw v. Briginshaw (1938) 60 CLR 336 at 361-362. 